\title{
Bye, bye blockbusters, hello niche busters
}

$\mathrm{T}$ he year 1975 was a lucrative time for a great white shark named Bruce. A mechanical beast weighing 1.5 tonnes, Bruce was the star of Jaws, a movie that grossed US\$260 million in the United States, ushering Hollywood into the summer blockbuster era. Like the movie industry, the pharmaceutical sector has in recent decades come to rely on annual blockbusters to drive profits. But it appears the blockbuster model is broken. Unless drug companies find new products to replace the many bestsellers with expiring patents or adapt in other ways, such as focusing on niche markets, they may be entering dangerous waters.

"Unless we reinvent ourselves through research, then we can face a bit of a dip, which is the situation we are in now," says Paul Lévesque, president of Pfizer Canada. "That said, our industry is cyclical and this is not the first time we have faced a situation like this."

The so-called "blockbuster philosophy" that has dominated the pharmaceutical industry proposes that drugs should be developed for as many people as possible so as to achieve sales of at least US\$1 billion. According to a recent analysis of growth rates of spending on prescription drugs in the United States, the number of products achieving that goal has been shrinking over the past few years (Health Affairs 2009;28:w151-60).

From 1997 to 2006, the paper states, the number of US blockbuster drugs grew from 6 to 52. In 1996, blockbusters accounted for only $12 \%$ of drug sales. A decade later, that percentage had swelled to about 50\%. Pfizer's bestseller atorvastatin (Lipitor), dubbed by some "the ultimate blockbuster," generated worldwide sales of US $\$ 13.6$ billion at its peak in 2006.

But many of those mega-sellers including atorvastatin, fluticasone propionate (Flonase), clopidogrel bisulfate (Plavix) and sildenafil (Viagra) - have come off patent or will in the near

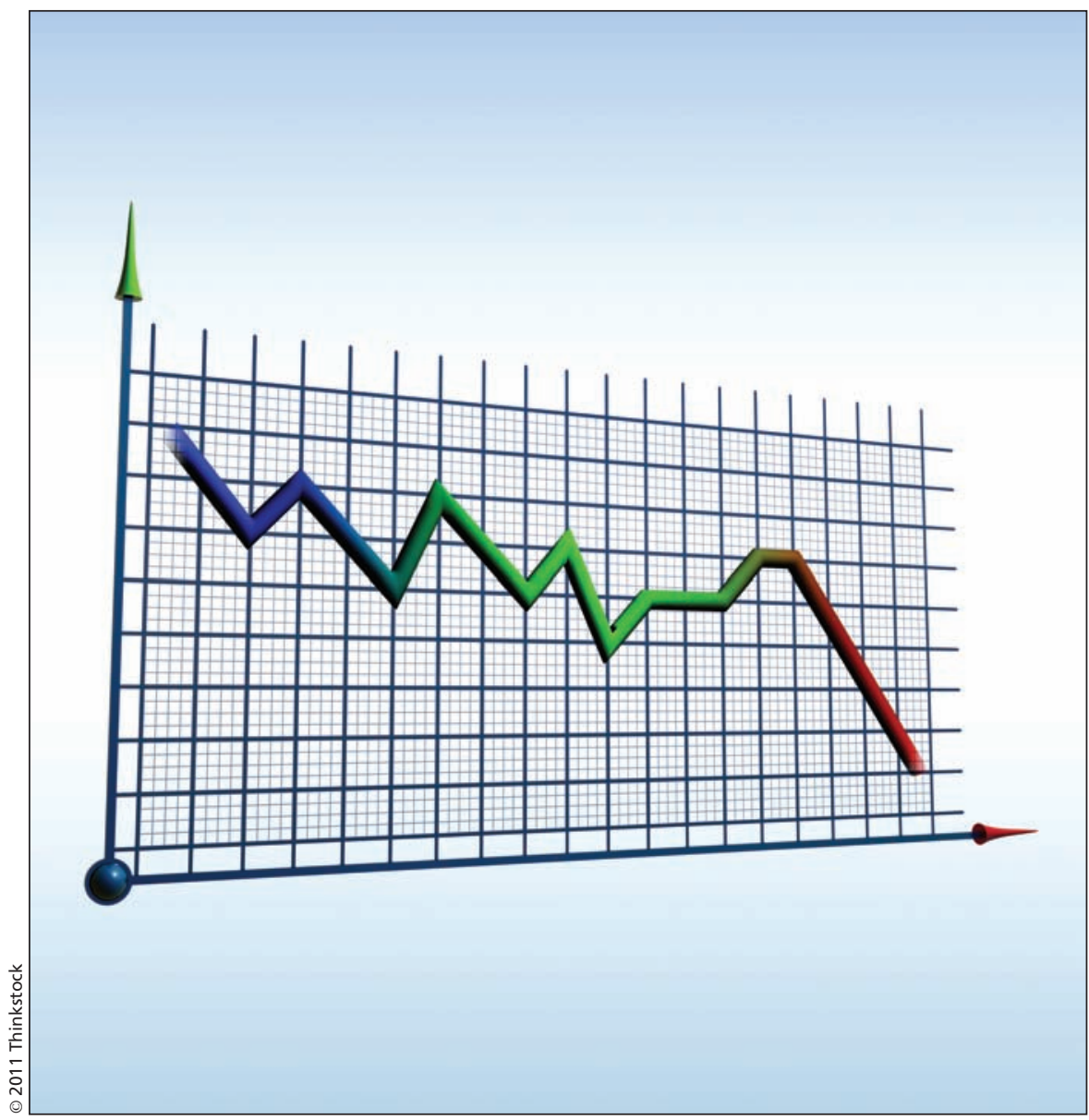

The pharmaceutical industry appears puzzled about how to respond to a decline in sales prompted by the expiry of patents on "blockbuster" drugs.

future. In 2007, the number of blockbusters fell to 48 and accounted for $44 \%$ of all drug sales. Meanwhile, the percentage of US prescriptions filled with generic drugs is increasing rapidly, jumping from $51 \%$ in 2002 to $67 \%$ in 2007. Overall, the growth rate of spending on prescription drugs in the US fell to $1.6 \%$ in 2007 , the lowest it's been since 1974 .

"Slow sales growth is likely to put pressure on research budgets and marketing costs and to create incentives for mergers," the study states. "The existence of fewer, larger entities with tighter research budgets may stifle or limit investment in innovation and the ongoing prospects for improved therapeutics reaching the market."
Lévesque isn't so pessimistic about the state of his industry. He acknowledges that certain product categories are "satisfied" and are unlikely to produce more billion-dollar products. Still, he says, there is money to be made by targeting subpopulations within many categories. Furthermore, there are still diseases that aren't fully understood, such as cancer and Alzheimer disease, so there is still potential for creating breakthrough pharmaceutical products.

"I think we are going to have a new generation of blockbusters," says Lévesque.

In the meantime, he says, drug companies will continue to merge and consolidate research efforts to increase productivity. That will likely spell bad 
news for countries such as Canada and the US, as even more clinical trials will move to other countries where it is cheaper to conduct them. Even if their sales decline, drug companies can ill afford to neglect research and development, says Lévesque. "You're only as good as your pipeline," he says. "You need to invest in research."

If drug companies are wise, they will invest in research to create treatments targeted at the people most likely to respond to them rather than on new therapies targeted at mass markets, says Jan Trøst Jørgensen, a 25-year veteran of the pharmaceutical industry who is now director of the Dx-Rx Institute, a research organization in Fredensborg, Denmark.

The major reason there are fewer blockbusters is because they have such low efficacy rates, according to Jørgensen. In many countries, there is immense pressure on governments to decrease health care costs. Governments and medical insurers no longer seem as willing to cover the costs of expensive products that offer little, if any, advantages over existing therapies.

"Normally new blockbuster drugs are sold at a premium of $20 \%$ to $40 \%$, but with today's financial situation this could be difficult," Jørgensen writes in an email. "Who will pay a premium of maybe $30 \%$ for a drug which is only $5 \%$ more efficacious than the established standard therapy?"

Drug companies should instead focus on increasing the efficacy of their products by developing them for smaller groups using a parallel drugdiagnostic model, says Jørgensen. By developing companion diagnostic tests for their new products, the companies would be able to stratify patients according to their genetic predisposition to respond to these therapies. This could create a more rational drug development process with less trial and error and higher efficacy rates, paving the way for personalized, or "stratified," medicine. It's a trend that several pharmaceutical firms say they are pursuing (www.cmaj.ca/lookup/doi/10.1503/cmaj .109-3714).

"Drugs developed under this model are likely to be more than $5 \%$ to $10 \%$ efficacious compared to the current standard therapy, and then be able to justify a premium price," writes Jørgensen. "What I see now is that we are slowly moving towards stratified medicine, which I believe will be the model that will replace the blockbuster model."

In a 2008 paper, Jørgensen noted that blockbuster medicines are created using a suboptimal "one size fits all" approach, with no regard for a patient's unique biology (Expert Rev Mol Diagn $2008 ; 8: 689-95)$. Entering the world of personalized medicine may not be as lucrative, suggests Jørgensen, but the pharmaceutical industry may have little choice but to change the way it does business.

"We have probably only seen the beginning of the decline in the number of blockbuster drugs and, if the big pharmaceutical companies are to avoid stagnation, a new business model needs to be developed," the paper states. "The companies will have to change their attitudes if they want to be among the winners in the future. The implementation of stratified or personalized medicine will definitely change medical practice over time, and those pharmaceutical companies who do not understand this message and adjust their strategy in time could be the losers." Roger Collier, CMAJ

CMAJ 2011. DOI:10.1503/cmaj.109-3874 